\title{
Capacitative Coupling
}

National Cancer Institute

\section{Source}

National Cancer Institute. Capacitative Coupling. NCI Thesaurus. Code C63283.

Problem associated with the transfer of energy within an electrical network by means of the capacitance between circuit nodes. It occurs when energy is coupled from one circuit to another through an electric field. 